\title{
INFLUÊNCIA DA COBERTURA MORTA NO COMPORTAMENTO DO HERBICIDA TRIFLURALIN ${ }^{1}$
}

\author{
BENEDITO N. RODRIGUES ${ }^{2}$, JOÃO DE LIMA ${ }^{3}$, INÊS F. U. YADA ${ }^{4}$ e DONIZETI A. FORNAROLLF
}

\section{RESUMO}

O objetivo do presente trabalho foi avaliar o comportamento de trifluralin em préemergência no sistema de plantio direto. O experimento foi conduzido na safra 1995/96, na sede do IAPAR Londrina/PR, utilizando-se palha de aveia-preta como cobertura morta. O delineamento foi o de blocos ao acaso com parcelas subdivididas e quatro repetições. Os tratamentos da parcela foram as quantidades de palha: zero, seis e 12t/ha de matéria seca e os da subparcela foram as doses de trifluralin: zero, $1200,2400,3600$ e $4800 \mathrm{~g} / \mathrm{ha}$ i.a. A cultura de verão foi a de milho, cv. AG-510. O herbicida foi aplicado com pulverizador de precisão $\left(\mathrm{CO}_{2}\right)$ munido com barra de $3 \mathrm{~m}$ e seis bicos 80.02 , vazão de $200 \mathrm{l} / \mathrm{ha}$ e pressão de $35 \mathrm{lb} / \mathrm{pol}^{2}$. Vinte e quatro horas após a aplicação do produto, foi feita uma irrigação de $20 \mathrm{~mm}$ para forçar a lixiviação do produto da palha para o solo. Antes e após a irrigação, foram feitas amostragens de solo e da palha para serem submetidas a análise de resíduos por cromatografia. Parte desse solo amostrado, foi utilizado em bioensaios, utilizando-se sorgo forrageiro como planta-teste. Pelos resultados observados no campo, nos bioensaios (fitotoxicidade no sorgo) e pelos resultados das análises cromatográficas de resíduos na palha e no solo, concluiu-se que trifluralin não atingiu o solo, mesmo com a irrigação efetuada. Apenas traços desse produto foram detectados no solo e na palha, tanto antes como após a irrigação.

Palavras chave: plantio direto; cromatografia; resíduo.

\section{ABSTRACT \\ Influence of the mulch on the behavior of Trifluralin}

The plant residues are the main part of the no-tillage system. Although these soil covers reduce weed population density, they might intercept herbicides when applied on the mulch. Field experiment, bioassays and chromatographic analysis were made using trifluralin at the rates: zero, 1200, 2400, 3600 and 4800 g.a.i/ha applied on 6000 and $12000 \mathrm{~kg} / \mathrm{ha}$ of oat residues and on soil without mulch. Soil and straw samples were collected immediately after trifluralin application.
Twenty four hours after trifluralin application the field was irrigated and more samples were collected for bioassays and chromatographic analysis. The results showed that the weed-crop competition was reduced under mulch conditions. The weed population were formed by Brachiaria plantaginea only. Trifluralin was not leached to the soil surface. This product was not detected neither in the straw nor in the soil after irrigation. residue.

\footnotetext{
${ }^{1}$ Recebido para publicação em 25/08/97 e na forma revisada em 16/10/98.

${ }^{2} \mathrm{Eng}^{\mathrm{o}} \mathrm{Agr}^{\circ}, \mathrm{PhD}$, Pesquisador, Instituto Agronômico do Paraná-IAPAR. C.P. 481, CEP 86001-970, Londrina/PR.

${ }^{3}$ Eng $^{\circ}$ Químico, MSc, Pesquisador, Instituto Agronômico do Paraná-IAPAR. C.P. 481, CEP 86001-970, Londrina/PR.

${ }^{4}$ Eng $^{\mathrm{a}} \mathrm{Agr}^{\mathrm{a}}$, MSc, Pesquisadora, Instituto Agronômico do Paraná-IAPAR. C.P. 481, CEP 86001-970, Londrina/PR.

${ }^{5}$ Aluno de pós-graduação, UEL. C.P. 2251, CEP 86100-000, Londrina/PR.
} 


\section{INTRODUÇÃO}

A cobertura morta, constituída por resíduos vegetais, desempenha importante papel no sucesso dos diversos sistemas agrícolas: serve como camada isolante, protegendo o solo das amplitudes térmicas diurnas, reduzindo a evaporação, mantendo o solo úmido mesmo durante longo período de estiagem, enriquecendoo em matéria orgânica e proporcionando ambiente favorável ao desenvolvimento das populações de invertebrados.

Segundo Almeida (1981), além dessas vantagens, a cobertura morta pode funcionar ainda como um valioso elemento no controle das plantas daninhas, pois um terreno com cobertura uniforme e espessa de resíduos, apresenta uma infestação bastante inferior àquela que se desenvolveria se o mesmo fosse nu.

As coberturas mortas, no entanto, diferem muito entre si quanto ao tempo que levam para se decompor e, também, quanto à capacidade de liberarem substâncias alelopáticas capazes de inibir a germinação das sementes de algumas espécies de plantas daninhas presentes no solo. Almeida (1988), utilizando diversas coberturas mortas, verificou que os resíduos da aveia são, depois do nabo-forrageiro, os que se decompõem mais rapidamente mas, dada a maior massa inicial produzida mantém, por mais tempo, maior quantidade de cobertura morta sobre o terreno. Daí, a sua superior capacidade de controlar as infestantes.

Diante disso, esse mesmo autor cita também que, em culturas de verão como soja, feijão e milho, semeadas no sistema de plantio direto sobre coberturas mortas densas, de lenta decomposição e com ação alelopática, há possibilidade de se reduzir ou até mesmo dispensar o uso de herbicidas. No entanto, muitos agricultores fazem exatamente o contrário; aumentam as doses dos herbicidas residuais em plantio direto, alegando que parte do produto fica retida na palha e não atinge o solo. Neste caso, evidentemente, está se desperdiçando produto, onerando o custo de produção e poluindo inutilmente o ambiente.

Sabe-se, também, que os mesmos herbicidas pré-emergentes que são recomendados no plantio convencional, em solo bem preparado, livre de torrões e restos vegetais, são utilizados numa situação, onde há grande quantidade de restos de culturas, ou seja, de coberturas mortas (Rodrigues \& Almeida, 1995), como é o caso do plantio direto.

Esse fato tem chamado a atenção de diversos pesquisadores. Estudos realizados por Pastana (1972) nos E.U.A., em solo série Cecil (barro-arenoso), mostraram que quando atrazine foi aplicado em solo com cobertura morta de aveia, o peso seco das plantas daninhas que ali se desenvolveram foi maior que em solo sem cobertura morta, sugerindo que parte do produto ficou retida na palha. A redução do peso seco das infestantes, em solo com cobertura, foi conseguida com o aumento da dose do produto. Bauman (1977), confirmando esses resultados, verificou que, em aplicações de atrazine sobre restos de centeio, $30 \%$ menos do produto atingiu o terreno do que quando pulverizado diretamente em terra nua.

Banks \& Robinson (1982) nos E.U.A., estudaram a influência da palha do trigo no comportamento do metribuzin no solo. Esse herbicida foi aplicado nas doses de 0,3, 0,4 e $0,6 \mathrm{~kg} / \mathrm{ha}$ i.a., com e sem cobertura morta sobre o terreno. A quantidade de palha presente no solo no momento da aplicação era de $8.900 \mathrm{~kg} / \mathrm{ha}$. Aplicou-se $8 \mathrm{~mm}$ de água por aspersão no mesmo dia do tratamento. Os resultados indicaram que menos de $1 \%$ do metribuzin aplicado alcançou o solo antes da irrigação. Por outro lado, quando as parcelas foram irrigadas logo após a aplicação, observou-se que $56 \%$ do metribuzin atingiu o solo.

Os herbicidas, no entanto, possuem solubilidades diferentes. Comparando a remoção dos herbicidas alachlor e metolachlor da palha de trigo, através de lavagem com água, Strek \& Weber (1982) verificaram que o metolachlor, por ser mais solúvel em água, foi significativamente mais lavado da palha do que o alachlor. Com isso 
presume-se que pode haver diferenças significativas no comportamento dos herbicidas, quando aplicados sobre determinado tipo de cobertura morta e submetidos ou não à lavagem por chuva ou irrigação.

A nível de Brasil, esses estudos ainda são incipientes. Rodrigues \& Almeida (1986) no IAPAR, Londrina/PR, estudaram a influência da cobertura morta no comportamento do metolachlor na cultura da soja, em plantio direto. $\mathrm{O}$ produto foi aplicado em pré-emergência, logo após a semeadura, na dose de $2,88 \mathrm{~kg} /$ ha i.a. Em seguida, os tratamentos com irrigação receberam $30 \mathrm{~mm}$ de água, com regador manual, imediatamente após a aplicação. $\mathrm{Na}$ oportunidade, verificou-se que havia $2466 \mathrm{~kg} / \mathrm{ha}$ de palha de trigo no local do experimento. Após a irrigação, coletou-se amostras de solo a $10 \mathrm{~cm}$ de profundidade, que foram armazenadas a $-18^{\circ} \mathrm{C}$ até o momento de serem analisadas por cromatografia. Os autores verificaram que o teor de metolachlor no solo com cobertura morta, foi menor que em solo sem cobertura, o que evidencia a retenção do produto na palha.

Posteriormente, Rodrigues (1993), em ensaios preliminares, verificou que o clomazone apresenta indícios de ser fortemente adsorvido à palha, mesmo com chuvas $(20 \mathrm{~mm})$ que caiam imediatamente após a aplicação. Esse mesmo autor verificou também que o imazaquin provavelmente não fica fortemente adsorvido à cobertura morta, mesmo ocorrendo a primeira chuva uma semana após a aplicação. Nesses trabalhos, no entanto, não foram feitas análises cromatográficas de resíduo na palha e no solo.

Fornarolli et al. (1997), estudando o comportamento do herbicida atrazine em cobertura morta de aveia-preta, concluiu que $85 \%$ desse produto é interceptado pela cobertura morta dessa espécie. No entanto, com uma chuva de $20 \mathrm{~mm}$ ocorrida 24 horas após a aplicação, praticamente todo o produto foi lixiviado da palha para o solo.

Dando continuidade a essa linha de pesquisa, delineou-se o presente trabalho, cujo objetivo foi estudar o comportamento do trifluralin $(600 \mathrm{~g} / \mathrm{l})$ quando aplicado sobre cobertura morta de aveia no sistema de plantio direto.

\section{MATERIAL E MÉTODOS}

O presente experimento foi realizado em condições de campo e em "telado" na Estação Experimental do IAPAR em Londrina/PR, que possui as seguintes características: clima Cfa da escala de Koeppen, solo tipo Latossolo Roxo distrófico, com horizonte A moderado, de textura argilosa (81\% de argila, $8 \%$ de silte e $11 \%$ de areia), fase tropical perenifolia e relevo suave ondulado.

Foi adotado o esquema de blocos ao acaso, com parcelas subdivididas, com quatro repetições. Os tratamentos principais, em número de três, foram constituídos pelas seguintes quantidades de cobertura morta: 0,6 e 12 t/ha de matéria seca de palha de aveia preta. Os tratamentos secundários, em número de cinco, foram constituídos pelas seguintes doses de trifluralin: 0, 1200, 2400, 3600 e 4800 kg/ha i.a. O produto utilizado foi o Premerlin $600 \mathrm{~g} / 1$. Os dados obtidos foram submetidos a análise da variância, utilizando-se o desdobramento de graus de liberdade para se estudar a regressão polinomial, tanto para níveis de cobertura morta como para as doses de herbicida. As subparcelas, constituídas pelas doses de herbicida, tiveram as seguintes dimensões: área total $=3 \times 7=21 \mathrm{~m}^{2}$; área útil $=2 \times 5=10 \mathrm{~m}^{2}$. Lateralmente a cada subparcela, foram deixadas faixas com 1,0 m de largura, não tratadas, que foram utilizadas como termo de comparação nas avaliações visuais, além de proporcionarem maior isolamento a cada subparcela. Nas cabeceiras das parcelas foram deixados arruamentos com 1,0m de largura para trânsito dentro do experimento.

Após a aplicação do herbicida dessecante glyphosate $(0,54 \mathrm{~kg} / \mathrm{ha}$ i.a. $)$ na cultura de inverno (aveia), foi feita a "rolagem" (passada de "rolofaca"). Em seguida o experimento foi estaqueado e as parcelas foram numeradas. Nas parcelas sem cobertura morta, a palha foi cortada rente ao solo com tesoura manual e em seguida, através de amostragens, foi obtido o peso da matéria seca de 
palha (6t/ha). Todo esse material foi distribuído nas parcelas sem corte de palha, formando, portanto, as parcelas com $12 \mathrm{t} / \mathrm{ha}$ de palha. A seguir foi semeado o milho cv AG 510 no sistema de plantio direto, ao espaçamento de $90 \mathrm{~cm}$ entre linhas. A adubação utilizada foi de $300 \mathrm{~kg} / \mathrm{ha}$ da fórmula 04-30-12.

Após a semeadura realizada dia 28/11/95, foi aplicado, em pré-emergência, o herbicida trifluralin. A aplicação foi feita com pulverizador de pressão constante $\left(\mathrm{CO}_{2}\right)$, munido com barra de seis bicos "Teejet Flat Spray" 80.02, distanciados $50 \mathrm{~cm}$ entre si ( $3 \mathrm{~m}$ de alcance), vazão de 200 1/ha. Vinte e quatro horas após a aplicação, o experimento foi irrigado, recebendo $20 \mathrm{~mm}$ de água por aspersão. A finalidade dessa irrigação foi forçar a lixiviação do herbicida da palha para o solo.

Imediatamente após a aplicação, e também após a irrigação, foram coletadas num quadrado de 20 x $20 \mathrm{~cm}$ amostras de palha e de solo na profundidade de 0 a $5 \mathrm{~cm}$. Parte destas amostras de solo foram armazenadas em sacos plásticos, a $-18^{\circ} \mathrm{C}$, até o momento de serem analisadas no laboratório e as outras partes foram colocadas em vasos plásticos, devidamente identificados, e levados para "telado" onde foram feitos bioensaios. As palhas amostradas também foram igualmente identificadas e estocadas a $18^{\circ} \mathrm{C}$, para serem analisadas posteriormente e quantificados os resíduos do herbicida.

As quantificações analíticas dos resíduos de trifluralin foram feitas no Laboratório de Ecofisiologia do IAPAR, através das técnicas de cromatografia de fase gasosa (GC) conforme métodos descritos por Thier \& Zeumer (1987).

Como bioensaio, foi utilizado o sorgo forrageiro como planta-teste para detectar a presença do trifluralin no solo. Nos bioensaios foram feitas medições de altura e peso da matéria seca da parte aérea do sorgo aos 20 dias depois da semeadura (DDS).

O ensaio de campo teve as seguintes avaliações: a) peso da matéria seca da Brachiaria plantaginea (única espécie de planta daninha presente) antes da colheita $\left(\mathrm{g} / \mathrm{m}^{2}\right)$; b) produção de grãos da cultura $(\mathrm{kg} / \mathrm{ha})$.

\section{RESULTADOS E DISCUSSÃO}

No experimento de campo, verificou-se que a infestacão de B.plantaginea era insignificante nas parcelas com cobertura morta (Figura 1). Aos 120 DDS, nas parcelas com cobertura de palha, o peso da matéria seca (M.S.) da parte aérea da gramínea não ultrapassou a 60 $\mathrm{g} / \mathrm{m}^{2}$, enquanto que nas parcelas sem palha, chegou a mais de $350 \mathrm{~g} / \mathrm{m}^{2}$. Foram necessários $3600 \mathrm{~g} / \mathrm{ha}$ de trifluralin nas parcelas sem palha, para que houvesse uma redução na produção de M.S. de B.plantaginea nos mesmos níveis obtidos por $12 \mathrm{t} / \mathrm{ha}$ de palha mas sem herbicida. O reflexo da vantagem proporcionada pela cobertura morta na produção de milho, pode ser observado na Figura 2. Nas parcelas sem cobertura, as produções foram sempre inferiores àquelas proporcionadas pelas parcelas com cobertura morta. Esses dados indicam que as doses desses produtos podem ser reduzidas quando aplicado sobre cobertura morta de aveia (acima de 6 t/ha M.S.) para o controle do capim-marmelada na cultura do milho. Resultados semelhantes foram obtidos por Fornarolli et al. (1997) com atrazine.

No bioensaio realizado em condições de "telado", verificou-se que a altura do sorgo obtida aos 20 DDS foi praticamente a mesma, em todas as doses de trifluralin, inclusive na dose zero, permanecendo entre 30 e $35 \mathrm{~cm}$ (Figura 3), nas parcelas com cobertura. Nas parcelas sem cobertura, no entanto, a altura do sorgo foi sendo reduzida, com o aumento das doses do produto, ficando entre 15 e $20 \mathrm{~cm}$ nas doses maiores. A determinação do peso da M.S. da parte aérea do sorgo aos 20 DDS (Figura 4), confirmou esses dados, mostrando que o peso ficou ao redor de $700 \mathrm{mg} / \mathrm{vaso}$ nos vasos com solo retirado das parcelas com cobertura, em todas as doses do produto. Em solos sem cobertura, no entanto, o peso da M.S. do sorgo foi reduzido com o aumento das doses do herbicida. Esses dados indicam que o trifluralin não atingiu o solo nas parcelas com cobertura morta. 
Influência da cobertura morta no comportamento do herbicida Trifluralin

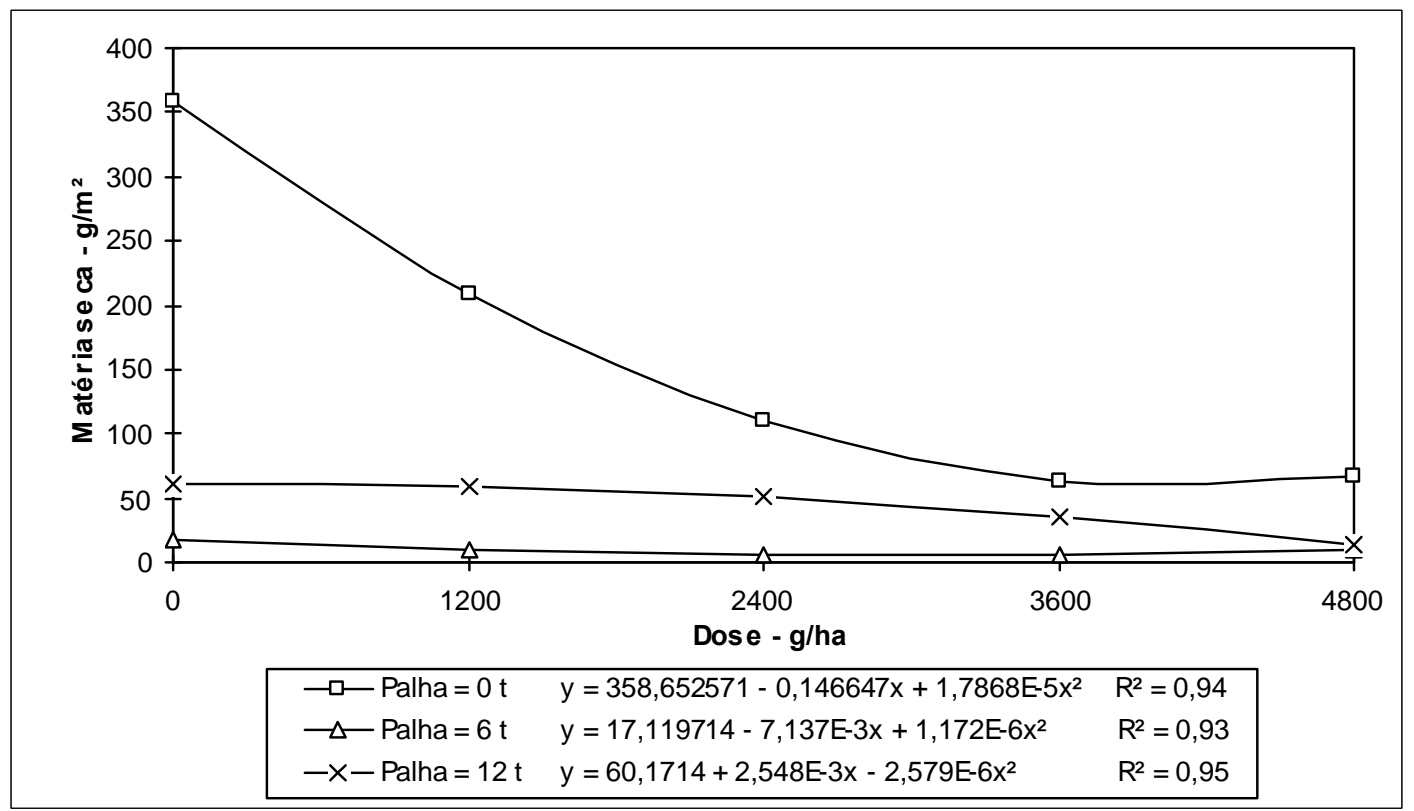

FIGURA 1. Influência da quantidade de palha e da dose de trifluralin no peso da matéria seca da $B$. plantaginea aos 120 DDS.

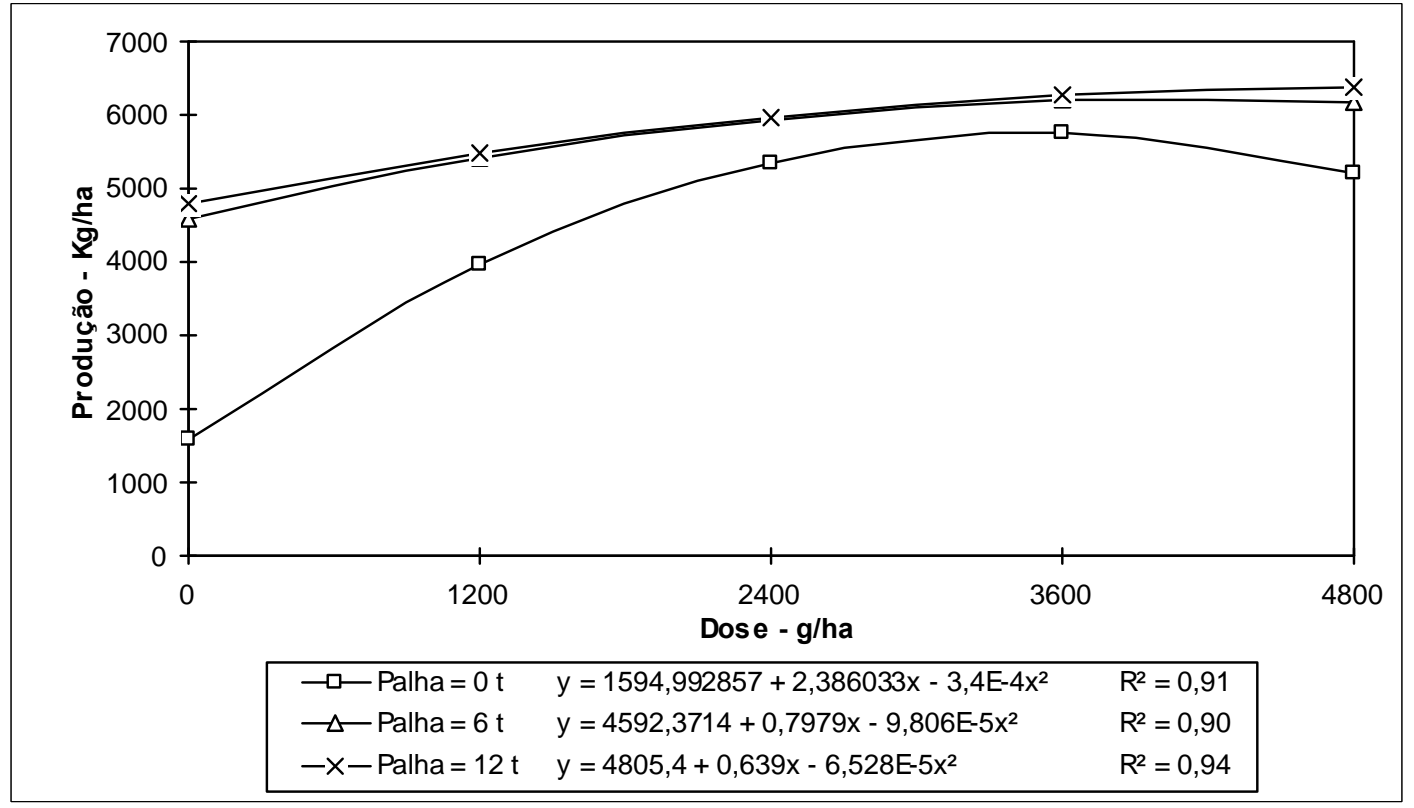

FIGURA 2. Influência da quantidade de palha e da dose de trifluralin na produção de milho. 


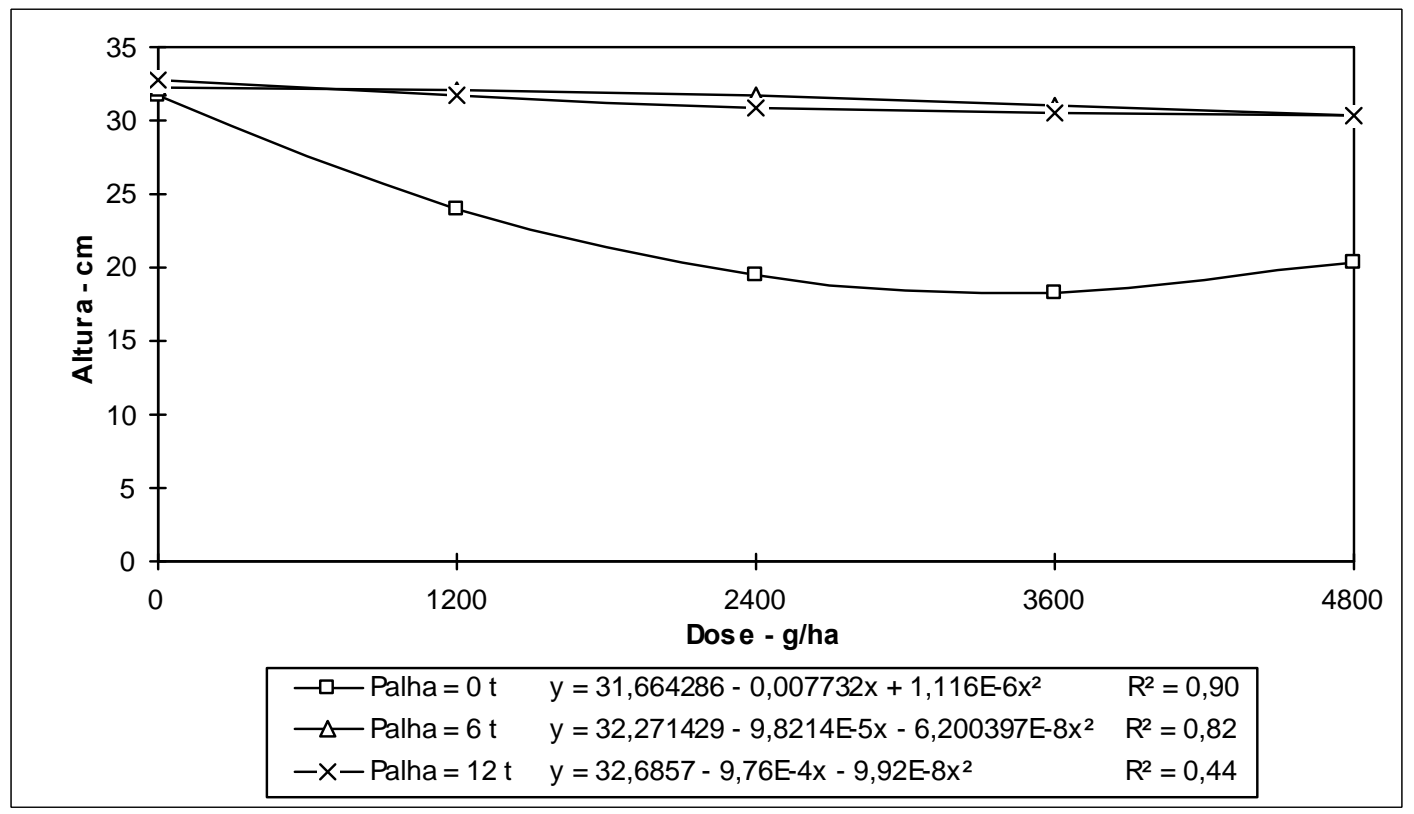

FIGURA 3. Influência da quantidade de palha e da dose de trifluralin na altura do sorgo aos 20 DDS com solo de 0 a $5 \mathrm{~cm}$ (Antes da irrigação).

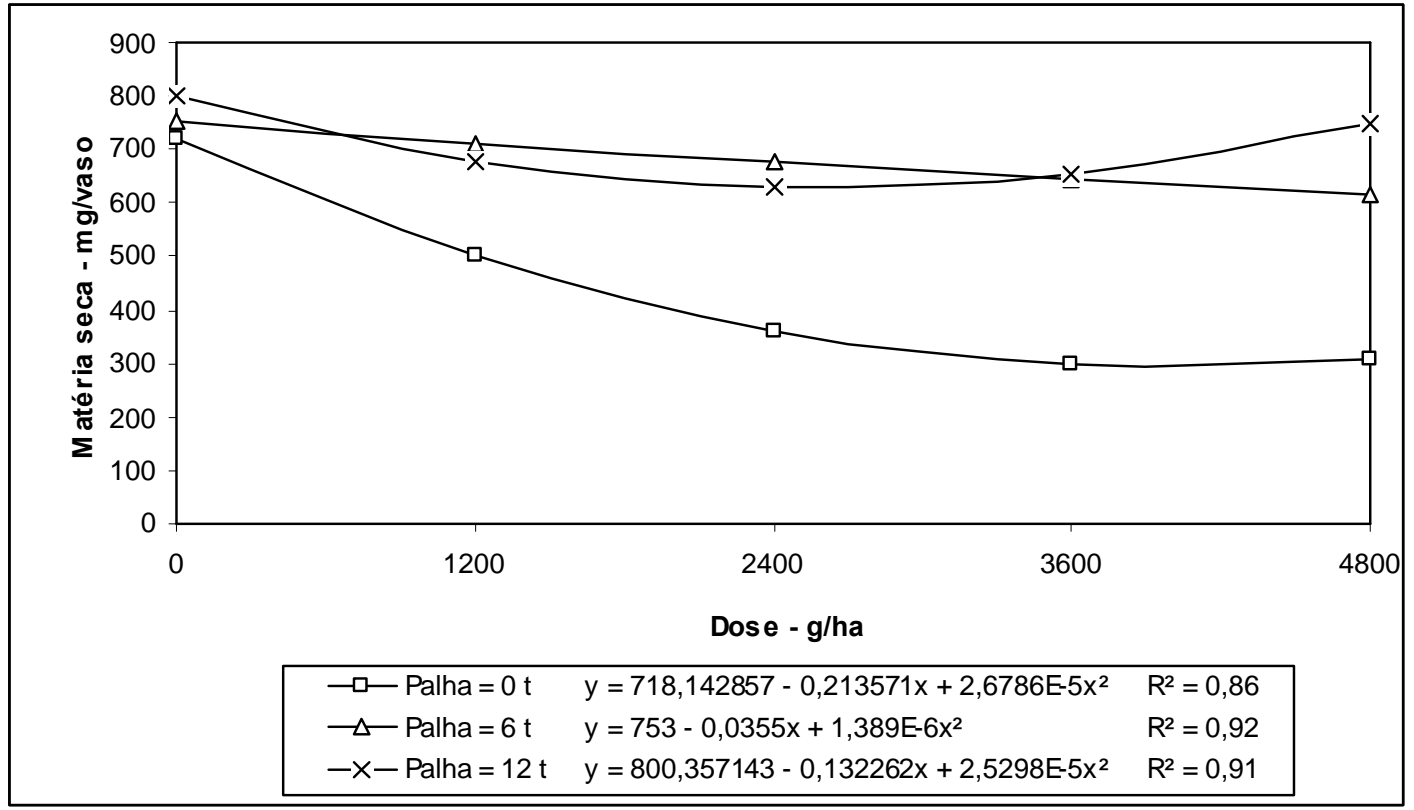

FIGURA 4. Influência da quantidade de palha e da dose de trifluralin no peso da matéria seca da parte aérea do sorgo aos 20 DDS com solo de 0 a $5 \mathrm{~cm}$ (Antes da irrigação). 
Para forçar a lixiviação do produto da palha para o solo, fez-se uma irrigação de 20mm, 24 horas após a aplicação do produto no campo. Nova amostragem de solo indicou, num segundo bioensaio (Figuras 5 e 6) que, nem assim, o produto atingiu o solo, uma vez que as Figuras 5 e 6 são semelhantes às Figuras 3 e 4 .

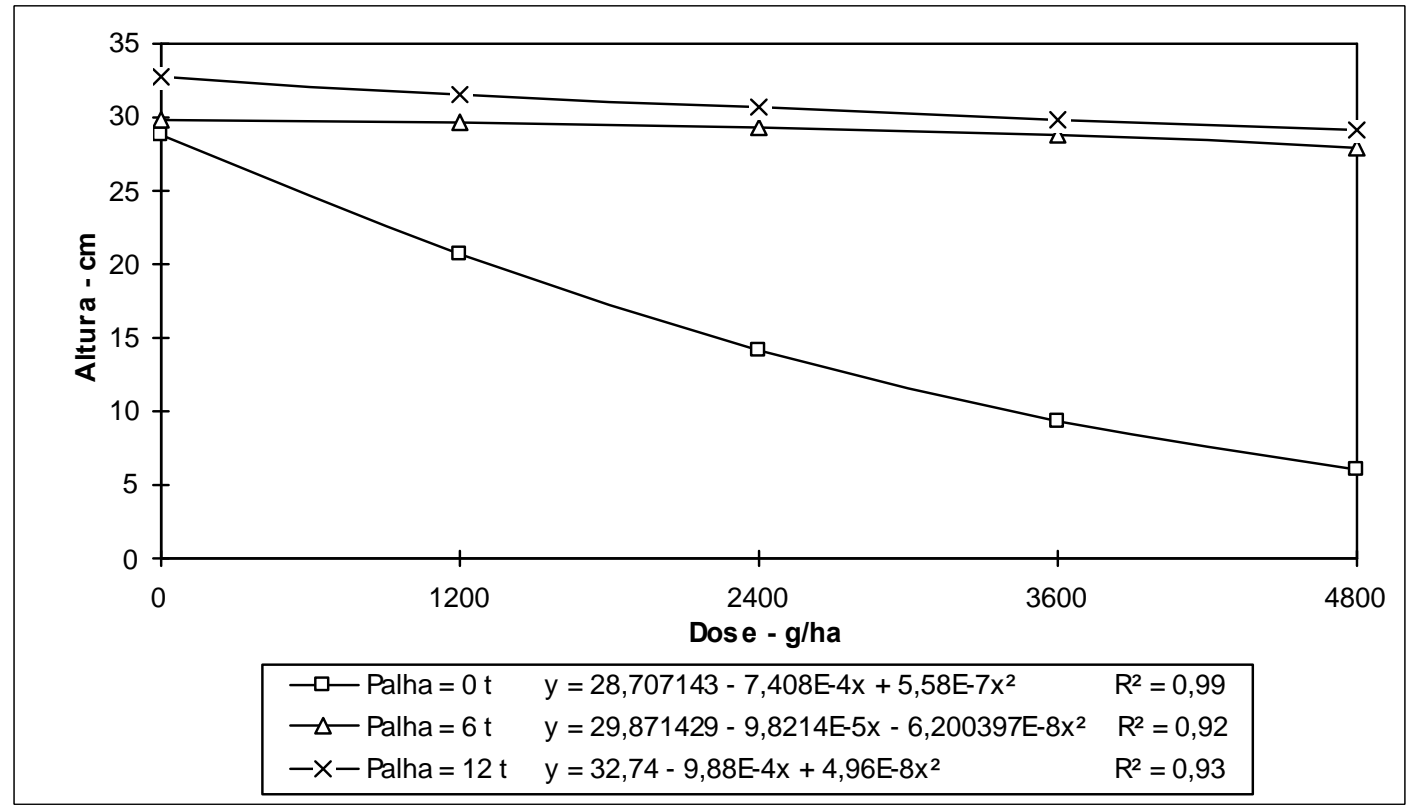

FIGURA 5. Influência da quantidade de palha e da dose de trifluralin na altura do sorgo aos 20 DDS com solo de 0 a 5 cm (Após a irrigação).

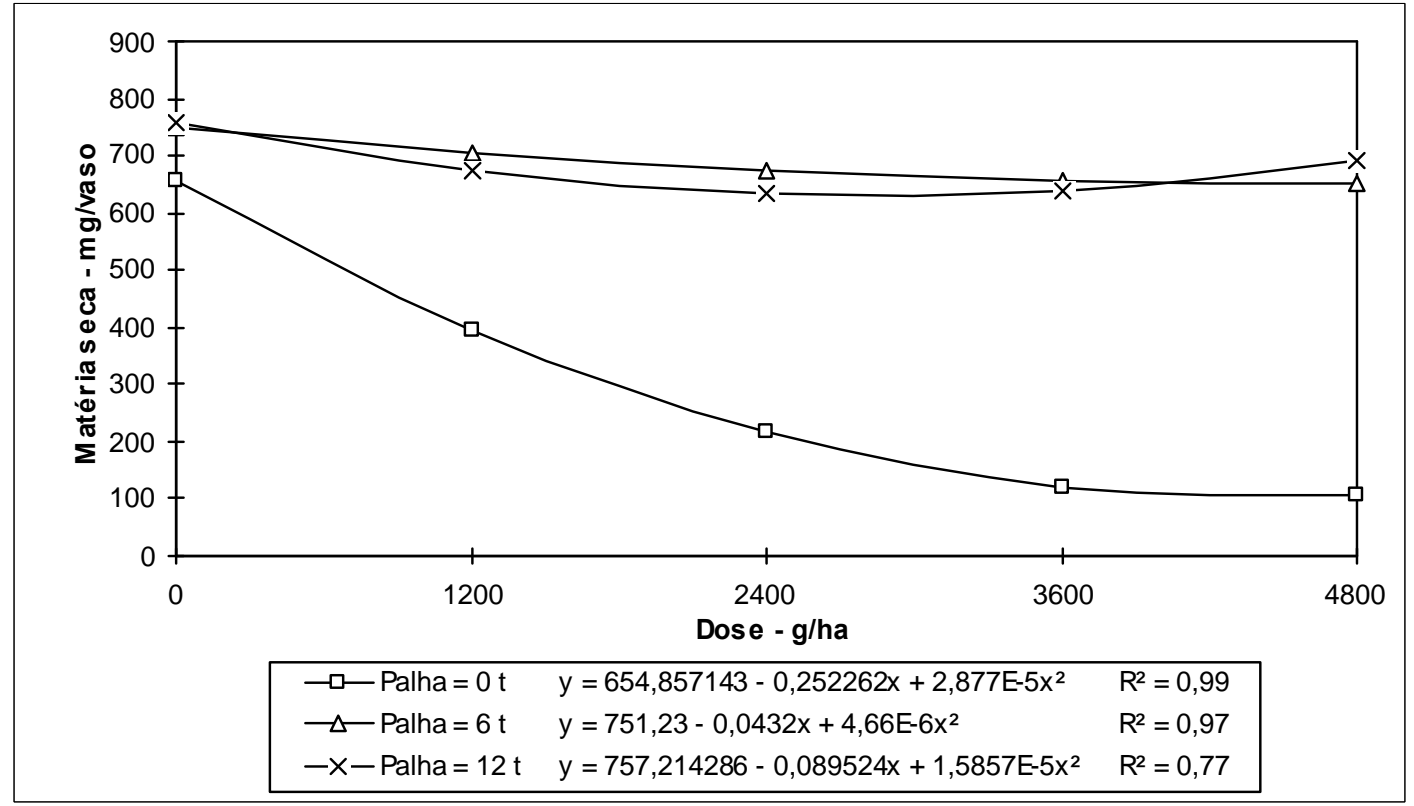

FIGURA 6. Influência da quantidade de palha e da dose de trifluralin no peso da matéria seca da parte aérea do sorgo aos 20 DDS com solo de 0 a 5 cm (Após a irrigação). 
Para se determinar o teor de trifluralin que realmente estava presente no solo antes e após a irrigação, realizou-se análises cromatográficas de resíduos desse produto. Pela Figura 7, observa-se que apenas traços do produto chegou ao solo nas parcelas com cobertura, antes da irrigação. Nas parcelas sem cobertura detectou-se aproximadamente $2000 \mathrm{~g} / \mathrm{ha}$ das $4800 \mathrm{~g} / \mathrm{ha}$ inicialmente aplicadas. Esses valores praticamente não se alteraram após a irrigação (Figura 8).

Fornarolli et al.(1997), ao contrário dos resultados obtidos no presente trabalho com trifluralin, verificaram que praticamente todo atrazine foi lixiviado da palha para o solo, utilizando metodologia semelhante. Pastana (1972) e Bauman (1977), também observaram retenção de atrazine na palha, sem irrigação.

Supondo-se que o trifluralin teria ficado retido na cobertura, realizou-se as análises cromatográficas de resíduos na palha antes e após a irrigação. Os valores observados antes da irrigação (Figura 9) mostram que o produto realmente ficou retido em parte na palha, ou seja, 400 a $500 \mathrm{~g} / \mathrm{ha}$ da quantidade inicialmente aplicada (4800 g/ha), o que corresponde a aproximadamente $10 \%$. Os outros $90 \%$ do produto foram perdidos. Após a irrigação, os teores detectados foram ainda menores, o que era de se esperar. Mesmo na dose maior, o valor obtido não ultrapassou a $300 \mathrm{~g} /$ ha (Figura 10).

Esses dados indicam que o produto não atingiu o solo nem antes nem após a irrigação em condições de cobertura morta de aveia preta. Isso pode ter ocorrido devido a volatilização rápida do produto da palha, não tendo condições de atingir o solo e ser incorporado pela água de irrigação.

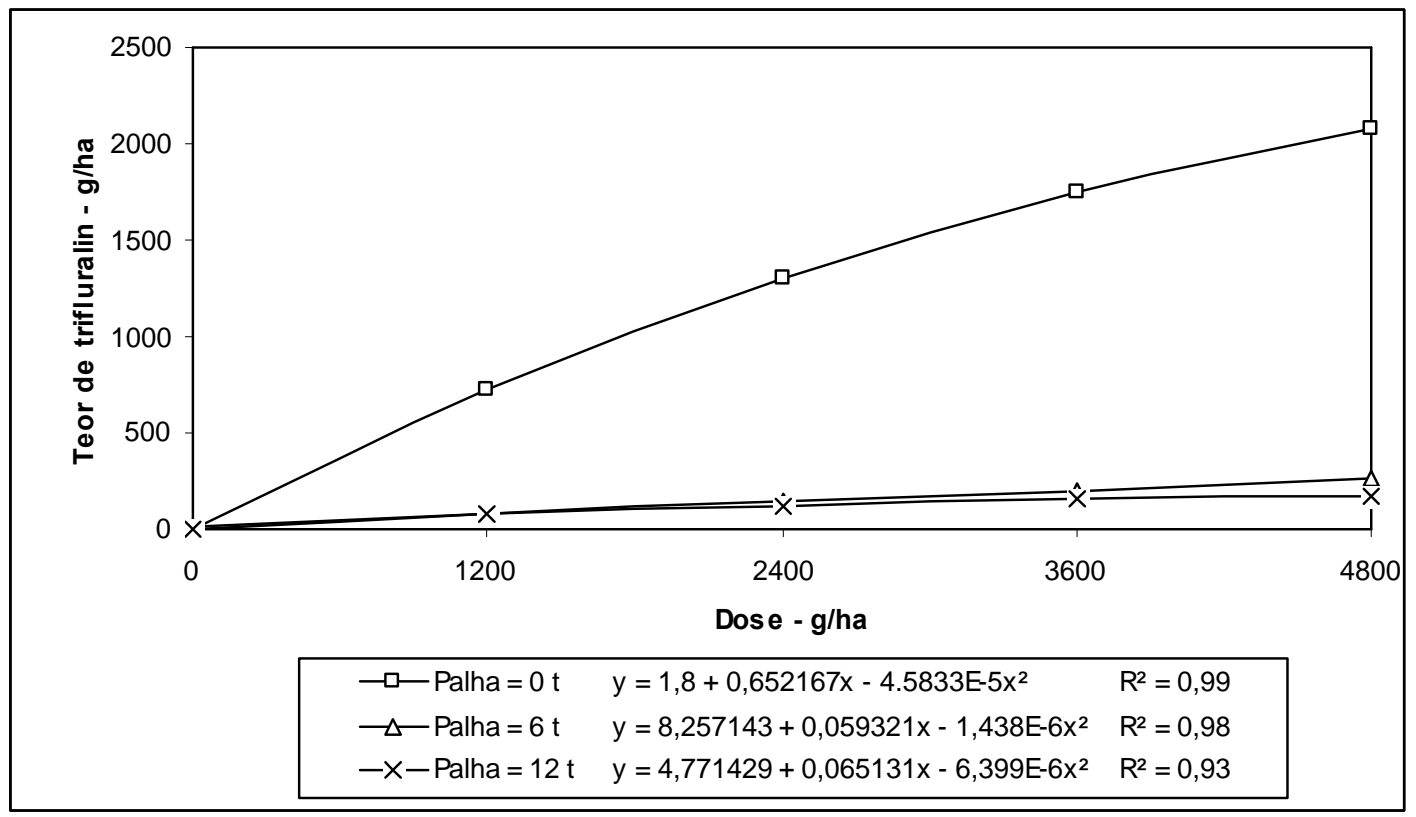

FIGURA 7. Teor de trifluralin no solo na profundidade de 0 a $5 \mathrm{~cm}$ (Antes da irrigação). 
Influência da cobertura morta no comportamento do herbicida Trifluralin

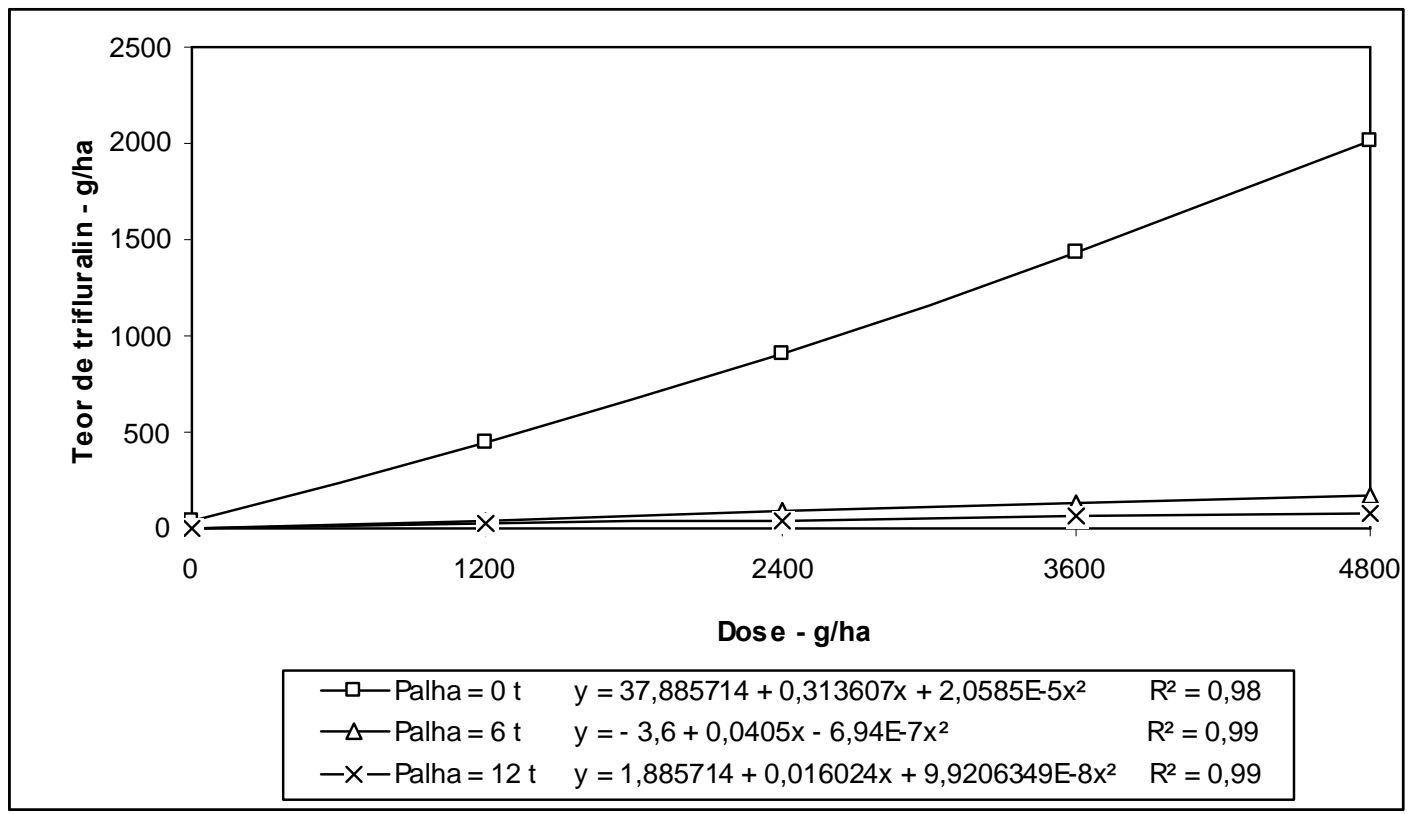

FIGURA 8. Teor de trifluralin no solo na profundidade de 0 a $5 \mathrm{~cm}$ (Após a irrigação).

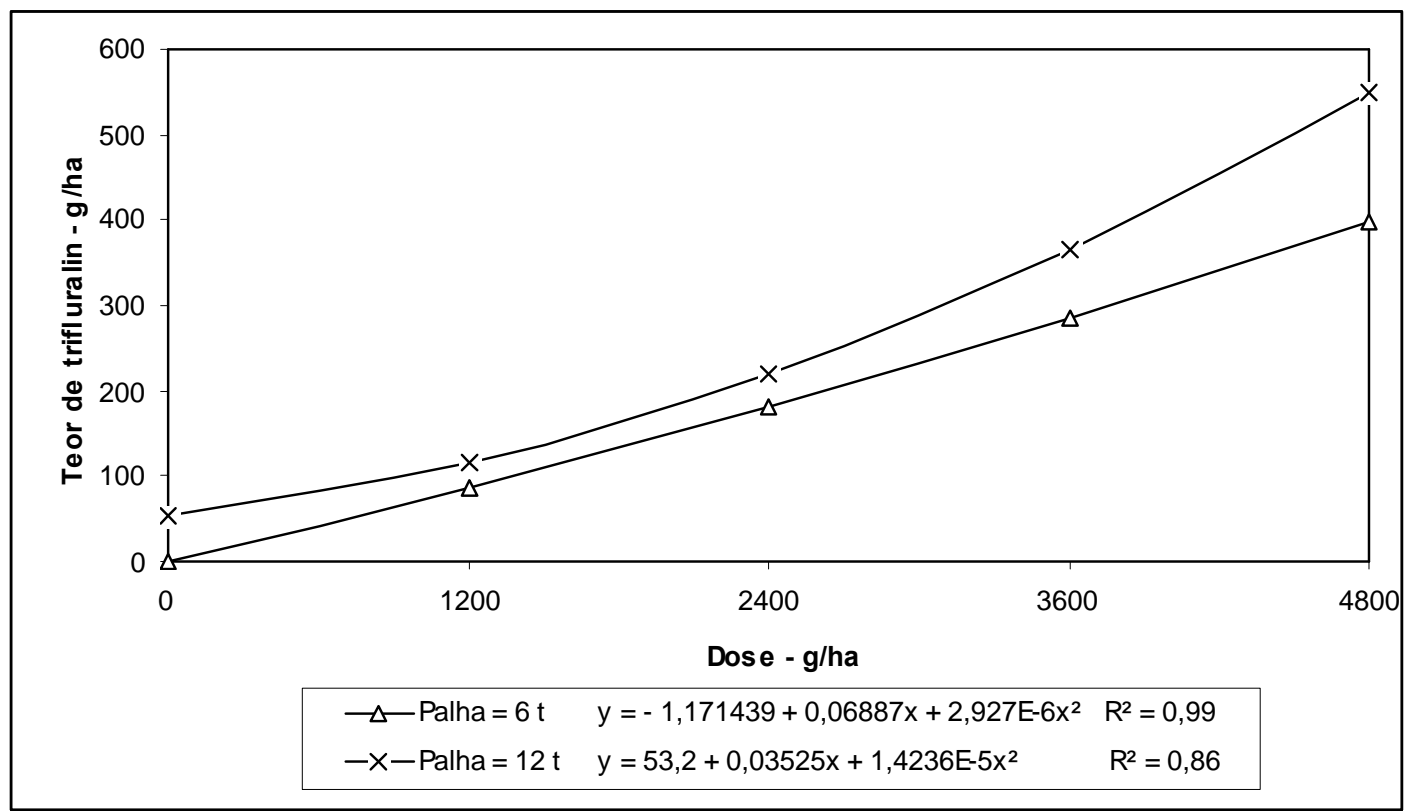

FIGURA 9. Teor de trifluralin na palha (Antes da irrigação). 


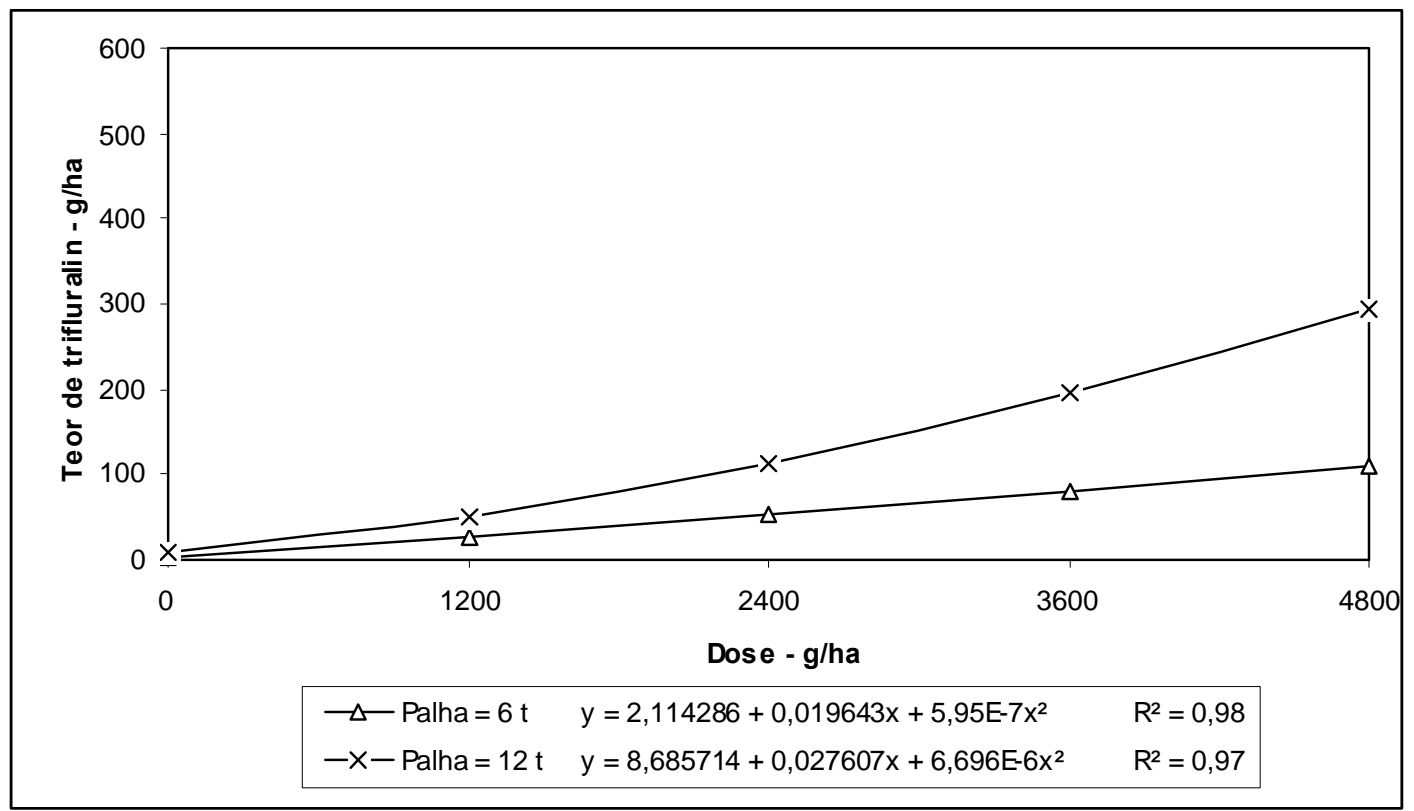

FIGURA 10. Teor de trifluralin na palha (Após a irrigação).

\section{LITERATURA CITADA}

ALMEIDA, F.S. Controle de ervas. In: IAPAR. Plantio direto no Estado do Paraná. Londrina, 1981. p. 101-44. Circ. Inst. Agron. Paraná, n. 23.

ALMEIDA, F.S. A alelopatia e as plantas. Londrina, IAPAR, 1988. 60 p. Circ. Inst. Agron. Paraná, n. 53.

BANKS, P.A., ROBINSON, E.L. The influence of straw mulch on the soil reception and persistence of metribuzin. Weed Sci., v. 30, n. 2, p. 164-8. 1982.

BAUMAN, T.T. Amount and persistence of atrazine in soil with three tillage systems. Dissert. Abstr. Int., v. 37, n. 10, p. 4795-5. 1977.

FORNAROLLI, D.A., RODRIGUES, B.N., LIMA, J., VALÉRIO, M.A. Influência da cobertura morta no comportamento do herbicida atrazine. In: CONGRESSO
BRASILEIRO DA CIÊNCIA DAS PLANTAS DANINHAS, 21, 1997, Caxambu. Resumos... Caxambu: SBCPD, 1997. p. 343.

PASTANA, F.I. Efeito da retenção de um herbicida pela cobertura morta do solo, no controle das ervas daninhas e na produção do milho com cultivo mínimo. Bragantia, v. 31, n. 22, p. 259-74, 1972.

RODRIGUES, B.N. Influência da cobertura morta no comportamento dos herbicidas imazaquin e clomazone. Planta Daninha, v. 11, n. 1 e 2, p. 21-8, 1993.

RODRIGUES, B.N., ALMEIDA, F.S. Influência da cobertura morta no comportamento dos herbicidas atrazine e metolachlor no sistema de plantio direto. In: FUNDAÇÃO INSTITUTO AGRONÔMICO DO PARANÁ. Resultados de pesquisa da Área de Herbologia, safras 1984/85 e 1985/86. Londrina, 1986, (Mimeogr.). 
Influência da cobertura morta no comportamento do herbicida Trifluralin

RODRIGUES, B.N. \& ALMEIDA, F.S. Guia de Herbicidas. 3 ed. Londrina: Ed. Autores, 1995, 675p.

STREK, H.J., WEBER, J.B. Adsorption, mobility and activity comparisons between alachlor (Lasso) and metolachlor (Dual). Proc.
Southern Weed Sci. Soc., v. 35, p. 332-8, 1982.

THIER, H.P., ZEUMER, H. Ed. Manual of pesticide residue analysis. Weinheim: VCH, v. 1, p. 383-400, 1987. 